\title{
The Design of Computer Music Teaching System based on Linux
}

\author{
Xinyuan Guo ${ }^{1}$ \\ ${ }^{1}$ Changsha University,Changsha,Hunan,China
}

\begin{abstract}
: the article takes music teaching information system as the research content, realize music appreciation collaborative model of teaching system based on WEB of Linux operating system. This will not only be able to take full advantage of the knowledge system optimization PAP principle, but also take project-based teaching model of collaboration technology to music education systems of information. The education systems include the $\mathrm{B} / \mathrm{S}$ structure framework for the development environment and build applications on multi-layered system architecture, in order to assist the music teaching activities.
\end{abstract}

Keywords: music appreciation, online teaching, B/S architecture, Linux operating system

\section{Introduction}

Traditional music teaching model is the "teacher-centered" and "teachers teach, students learn," which teacher to impart knowledge as the main purpose. In traditional music teaching, because single content and form, the lack of variability, resulting in unit volume of information within the narrow class and poor information transmission link, which greatly hindered the students more understanding of musical works, can not meet the students' works of different musical styles aesthetic needs. Educational model with traditional music and teaching methods, compared with rich multimedia music teaching system teaching content, reduce the burden on teachers to make the teaching process more interesting and many other advantages, for music teaching reform provides a new perspective. The topics in modern teaching philosophy under the guidance of the system into full play the advantages of multimedia teaching music, mainly from the cultivation of students' interest, the adjustment of teaching objectives, teaching content development, innovative teaching methods and teaching evaluation improvements in areas such as exploration, initial construction of a secondary student teaching new music creation mode. The model emphasizes covers music, performance and appreciation of the unity of coordination integrated teaching, so that students receive a comprehensive music creation, rich aesthetic experience, resulting in learning new realm of contemporary music gradually improve their own personality to create a quality, personalized comprehensive health development.

This paper studies and design music education system based on WEB, and analysis and research of the traditional teaching model, give full play to the advantages of online teaching, the design of functional, interactive and convenient music listening network teaching system. This network teaching based web, breaking the traditional teaching process in space and time limitations, maximize the students' self-learning ability, and users can interact in real time, creating a free and flexible teaching environment. In the analysis of the existing network system development status 
on the basis of teaching was proposed based on B / $\mathrm{S}$ structure of music appreciation network teaching system, the choice of development language as a front JSP, Java Bean implement server back-end business logic, MySQL as the backend database system, Linux the operating system. System development process accord to software engineering principles, the first systematic feasibility analysis, and fully understand user needs, analysis of different roles users of the system requirements, and then the system design and detailed design of the system, dividing functional modules, give specific data flowchart, the final coding implementation.

\section{Requirements analysis of system functional for music appreciation teaching system}

Music Appreciation teaching system is an improvement of existing teaching methods and supplements, but also information and network development is an inevitable trend. After research needs analysis, network teaching system's principal activities include the following aspects:

1) Students and teachers User Management: Students and teachers are the main network teaching system, their activity in the system directly reflects the function of the system. Students and teachers use the system function, you must first have a legitimate user privilege of account, and you can use the system functions properly after successful login system. Therefore, the management of the student teachers is mainly reflected in the user adds students, teacher's users, audit user's legitimacy, cancellation of illegal users and so on.

2) Course management: The main is to manage the release of curriculum and teachers. Each course need to publish in the system above, when released, including the name of the course, the course brief. Each course need to specify a classroom teacher, classroom teacher at the specified time, and select courses last time and place where the classes and courses.

3) Teaching Resources upload download: The main course of the relevant information, courseware for uploading and downloading operations. Each course can have guidance materials, courseware and other resources, teachers will be uploaded to the information system, the corresponding class of the course the students $\log$ into the system, and you can download on the site system above.

4) Announcement: mainly refers to teachers' learning and job exams published announcements. For some of the important process of teaching a notification message, such as exam notifications, class time or location changes, etc., after teachers in the $\log$ can publish directly on the site; these messages announcements will be presented in the form is very intuitive for students entering the system front of the user.

5) Online Test: mainly refers to the teacher via web publishing program of tests: a job or exams. Student users log system, directly into the test, answers to questions submitted online. Answers submitted to the system, the system will be based on the student's answer correct answer to judge and give students the final test results. Meanwhile, the system will also be on students 'test case gives intuitive statistics, such as students who take the test, students' average test grading.

6) Online Communication: mainly refers to students and teachers through the website system users online exchanges. Online communication is divided into two forms, one is a student teacher questions directly to teachers through Q operation answering students' questions; another is a student, teacher users to exchange for a discussion of issues, all of the normal user access to the system can participate. 


\section{Analysis of teaching system functional modules}

\subsection{Manager subsystem}

Subsystem is composed of user management, bulletin management, resource management, and educational administrators' four functional modules by the system administrator. As shown in Figure 1.

(1) The system user management. Administrators can add, delete users, and view user information, setting user permissions.

(2) Notice Management. Administrators can notice issued to teachers for review, add, or delete operation, while the students released some malicious messages and delete the information.

(3) Resource management. The system administrator is responsible for managing a variety of teachers upload learning resources, job training, examination questions and other data resources.

(4) Teaching management. Administrators need for all school classes and their teachers, and make reasonable arrangements for the deployment, balanced faculty, in order to successfully complete the teaching program.

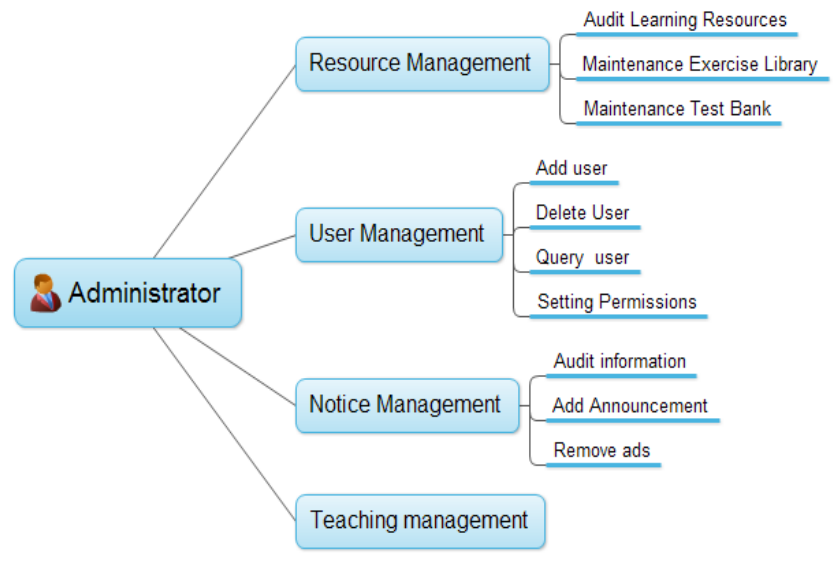

Fig 1 Administrators use case diagram

\subsection{Teachers subsystem}

Teacher's subsystem is consists of project management courses, teaching management, classroom management, these three functional blocks shown in Figure 2.

(1) Evaluation. Teachers understand relevant information of school students, and teacher can draw a evaluation data on all aspects based on student test scores and their job completed, individualized help students improve academic performance.

(2) Curriculum design. Teachers can upload and change the course-related information, including: course descriptions, syllabi, lesson plans, courseware, and other types of video learning materials that can be used for online teaching and student self-study after class download.

(3) Information dissemination. Teachers can bulletin released in the course of relevant information, including: class time, test time, adjusting school hours, job arrangements. This will enable the students to keep abreast of the class arrangement.

(4) Online Q \& A. This feature is very important, which is the mutual exchange of teachers and students a platform, teachers can promptly answer students 'autonomous learning in class and any problems encountered in the process, help to learn to solve problems, said the students' learning efficiency.

\subsection{Student subsystem}

Student's subsystem includes browse announcements, download information, current classroom blackboard, classroom assignments answer, online discussions and other functional modules, shown in Figure 3.

(1) Online learning. This feature is most critical for student users. Students can upload syllabus according to teachers, teaching music 
appreciation program to understand the teaching of this course arrangements to guide their own learning, and can download learning materials in the after-school, independent study. For do not know where, you can repeatedly watch videos, view data, and can be completed online teacher assignments, and online testing.

(2) Online Q \& A. Students in the learning process will always encounter some problems, online Q \& A for students or between students and between teachers build a good platform to help students find the answers to questions in a timely manner, untied doubt. User roles in learning to enter the online Q \& A subsystem

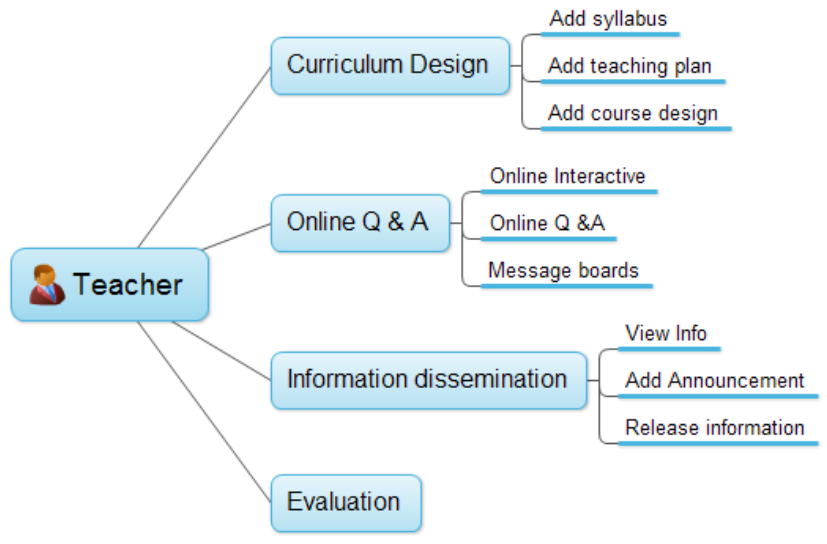

Fig 2 Teacher use case diagram

\section{System design of teaching for music appreciation}

\subsection{System framework}

This system uses B / S structure, so the client does not need to install the client software, which runs on top of the client's browser, system upgrades or maintenance can simply update the server-side software, thus greatly simplifies the client computer load, reducing system maintenance and upgrade cost and effort, with teachers answering system user roles under basically the same, just different roles have been different operating authority.

(3) Query results. Students can enter the query results after taking the test page to keep abreast of their test scores, this page will record each student test scores, and students are compared and summarized.

(4) View announcement. Students can view a variety of courses teachers publish relevant information about the curriculum and the administrator's announcement, easy to complete the learning task.

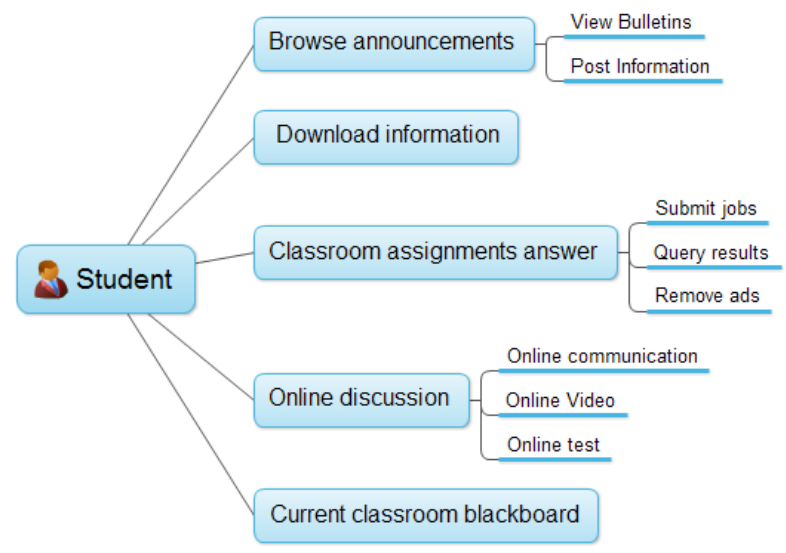

Fig 3 Student use case diagram

reducing the user's overall costs. System architecture is shown in Figure 4. System connects a web server user's browser through an Internet. Users open the IE browser, enter the appropriate address in the address bar, and then enter the login screen, enter your user name and password, and select the corresponding role, you can $\log$ in to the system. The flow is shown in Figure 5. 


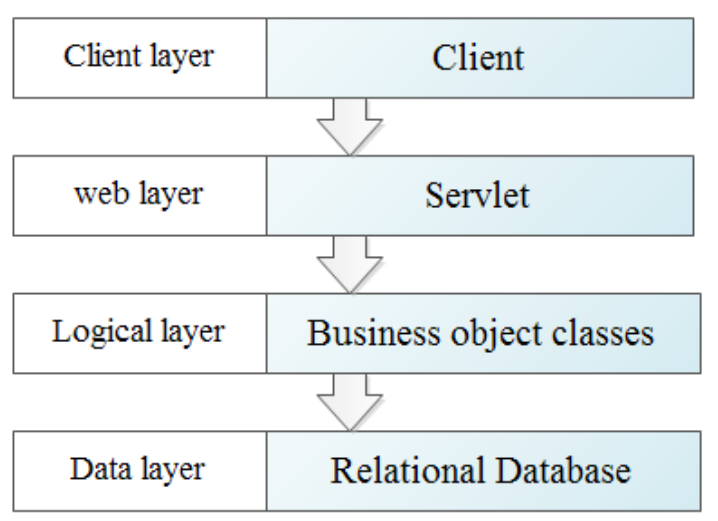

Fig 4 System framework

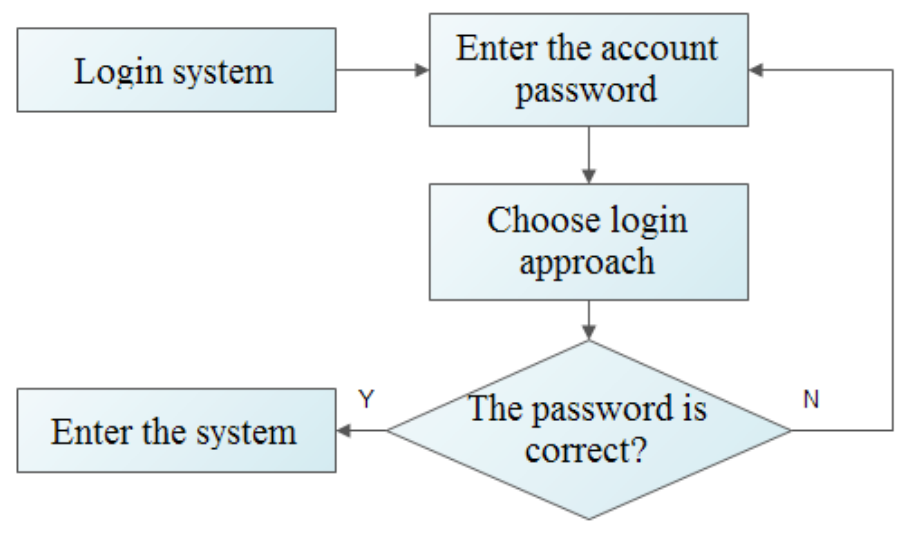

Fig 5 Login system processes

\subsection{The features modular design of music network teaching system}

Our system is divided into seven functional blocks, as shown in Figure 6. Users are also different functional module in different roles and permission. For example, student users only View
Bulletins Announcement manage permissions, and teachers user has permission to edit the announcement, the system administrator, you can view, publish, delete announcement.

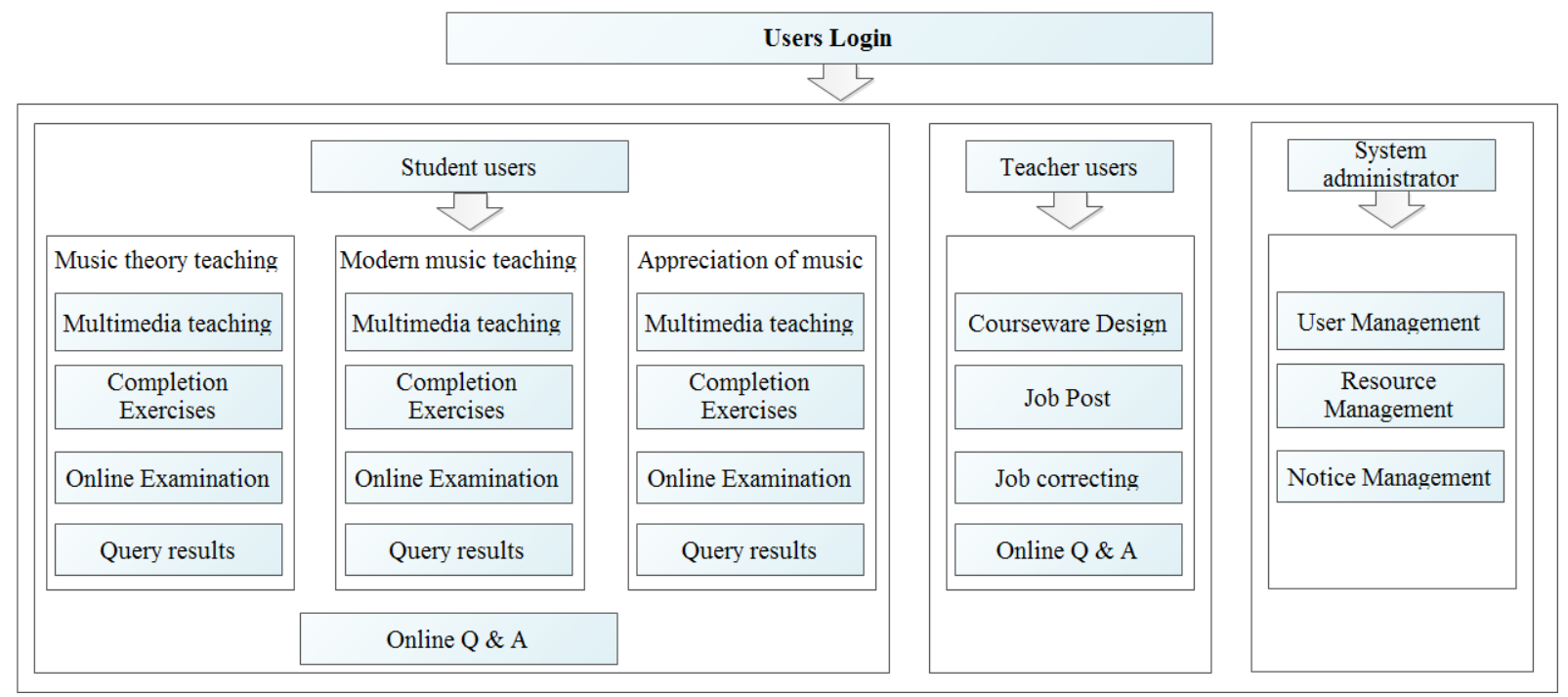

Fig 6 System function modules

\section{The design of database}

In the design process of network teaching platform, the database occupies a very important position; it would achieve the effect of impact. To ensure data integrity, enhance data storage efficiency, and then they would have a reasonable database structure design. Design a database; you use the correct data structure, to ensure that each database tables are no errors in the distribution. We take SQLServer2000 as back-end database systems, which design 21 user tables.

\section{Conclusions}

Article introduced teaching music appreciation for the detailed design based on B / S structure 
and completed the design of the overall framework for the system, followed by detailed system functional module design, followed by the design of the database include structural design and logic design, and finally the network layout. This chapter begins with software design, hardware design and then, from concept design to functional design, from a different perspective on the complete system design, system application and implementation of the foundation.

\section{Acknowledgement}

The 379 provincial general subject: Practice and reform of the ethnic dance teaching in universities

\section{Reference}

[1] Anderton, Craig. Cakewalk Sonar Producer Edition 3.0 - Lovely Look, Potent Plugs, Efficient Engine, Better Buses, http:// www.findarticles.com. 2004

[2] Rob G In-depth Feature: Cakewalk Sonar 2.0. http:// www. sonicstate. com. 2004

[3] $\mathrm{Wu}$ Yun. Marginalized status of music education in rural areas $[\mathrm{J}]$. Southwest Agricultural University: Social Sciences, 2007.5 (2): $176-178$. 